\section{Abstract}

\title{
Crystallisation of minerals from concentrated saline dairy effluent
}

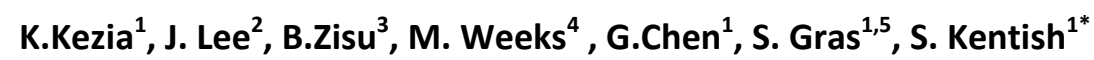 \\ 1. The ARC Dairy Innovation Hub, Department of Chemical and Biomolecular Engineering, University of Melbourne, Vic 3010 Australia \\ 2. Department of Chemical and Process Engineering, University of Surrey Guildford, Surrey GU27XH United Kingdom \\ 3. School of Applied Science, College of Science, Engineering and Health, RMIT University Melbourne, Vic 3000 Australia \\ 4. The ARC Dairy Innovation Hub, Dairy Innovation Australia, 180 Princes Hwy, Werribee, Vic 3030 Australia \\ 5. The Bio21 Molecular Science and Biotechnology Institute, University of Melbourne, Vic 3010 Australia
}

An understanding of crystallisation within saline effluents is important for the design of both brine crystallisers and brine disposal ponds. In this work, crystallisation of a saline effluent concentrate from the Australian dairy industry has been examined at $22 \mathrm{wt} \%$ and $30 \mathrm{wt} \%$ total solids and at temperatures between 10 and $70^{\circ} \mathrm{C}$. The precipitation occurs more rapidly at higher temperatures. This trend is dictated by precipitation of calcium phosphate salts, albeit the major constituents of the mixture are $\mathrm{NaCl}$ and lactose. The crystallisation induction time can be shortened by introducing cavitation induced by ultrasound. In particular, the use of two short acoustic pulses between $3.7 \mathrm{~J} / \mathrm{g}$ and $16 \mathrm{~J} / \mathrm{g}$ at $20 \mathrm{kHz}$ spaced ten minutes apart has maximum impact upon both induction time and crystal size. It is believed that the first ultrasound pulse either generates new nuclei or enhances the mass transfer of solute toward the surface of sub-micron growing crystals. Conversely, the second pulse disrupts the growing crystals and forms secondary nuclei. The ultrasound cannot shift the solution equilibrium and so is not able to improve the low crystal yield. To increase this total yield, further evaporation is necessary. The work provides direction to personnel in the dairy industry of the feasibility of brine crystallisation with respect to energy demand and solid recovery.

Keywords: Dairy; crystallisation; calcium phosphate; sodium chloride, ultrasound. 
The dairy industry is a major rural industry in Australia and generates $11 \mathrm{GL} / \mathrm{y}$ of liquid effluent (Blaschek et al. 2007). This effluent predominantly comprises waste from cleaning-in-place processes (CIP) and the salty whey by-product from hard cheese manufacturing. While traditionally, this waste has been handled by municipal water authorities; their continuing ability to do so is declining due to environmental constraints and increasing costs. This means that dairy companies can be forced to treat such saline waste on site; either through brine evaporators and crystallisers or the use of brine evaporation ponds. However, the efficiency of these units is limited by the energy consumption, the mass transfer driving force and fouling deposition. A better understanding of the crystallisation of salts from these wastes could allow crystallisation at lower salt concentrations, leading to energy reduction; or alternatively could assist in fouling mitigation.

The crystallisation process follows a number of fundamental steps, including nucleation, crystal growth, agglomeration and recrystallisation. The crucial driving force for both nucleation and growth is the supersaturation level. This supersaturation condition can be induced by addition of an antisolvent, solvent evaporation, shifting the $\mathrm{pH}$ or by temperature change. Primary nucleation can either be homogeneous, in the absence of a solid surface, or heterogeneous where a foreign surface such as the container wall, impeller or the surface of a membrane is used (Mullin 2001, Ruecroft et al. 2005, Yu et al. 2007). On the contrary, secondary nucleation occurs when a crystal seed presents in the system. In practice, homogenous nucleation is an uncommon process which only takes place at very high levels of supersaturation. On the other hand, heterogeneous nucleation can occur even at low supersaturation levels. The precise nucleation mechanism is often difficult to determine, since many compounds possess a wide metastable zone which leads to large variability. The history of the solution as well as the rate at which the supersaturation condition is reached can all govern the 
calcium phosphate is present, the dissolution of less stable phases and growth of more stable ones

52 (re-crystallisation) also influences the final crystal size distribution.

The ability of ultrasound to reduce the induction time before crystals are observed has been widely investigated (Bund et al. 2007, Bund and Pandit 2007a, Kordylla et al. 2008, Li et al. 2006, Li et al. 2003, Ruecroft et al. 2005, Wohlgemuth et al. 2010). Ultrasound creates cavitation bubbles which undergo cycles of compression and growth before collapsing. The implosion of these microbubbles within the solution generates localised extreme pressures and temperatures. It is argued that these extreme conditions can shorten the nucleation time by allowing the nucleation energy barrier to be more readily overcome. The shockwaves generated by the implosion events also enhance the mass transfer of solutes toward the growing nuclei and breaks down crystal aggregates to create more surface area for crystal growth(Wagterveld 2013). The application of ultrasound can also influence the crystal size distribution, uniformity and morphology.

In the dairy industry, ultrasound has been applied to assist in lactose crystallisation from concentrated solutions and the sweet whey produced from cheese manufacturing (Bund and Pandit 2007b, Dincer et al. 2014, Kougoulos et al. 2010, Zamanipoor and Mancera 2014, Zisu et al. 2014). However, the precipitation of minerals from saline dairy effluent has not yet been extensively investigated due to the interference of impurities as well as its low economic value. Saline dairy effluent generated in the industry can contain $\mathrm{NaCl}$ at very high concentrations due to the deliberate addition of this salt during the production of hard cheeses. Furthermore, a considerable amount of residual lactose and calcium phosphate is usually present in the mixture. This effluent can be concentrated to a certain level through reverse osmosis, membrane distillation and/or evaporation technologies. However, calcium phosphate precipitation and scaling currently limits the concentration level that can be achieved (Amjad 2013, Kezia et al. 2015, Rice et al. 2009a, Rice et al. 2009b, Schäfer et al. 1998). Selective crystallisation of the calcium phosphate as an intermediate step would thus allow these processes to further concentrate the effluent. The calcium phosphate 
may also have value as a food additive. Alternatively, bulk crystallisation of $\mathrm{NaCl}$ and calcium phosphate as a mixture would allow more efficient disposal of the solid content following concentration.

This study focuses on the feasibility of precipitating these salts from saline dairy effluents at high concentration. To minimize the energy demand, the feed effluent is first concentrated using membrane distillation at $50^{\circ} \mathrm{C}$. Under these relatively mild conditions, the total dissolved solids concentration that can be achieved is limited to $\pm 30 \mathrm{wt} \%$, of which $\pm 24-25 \mathrm{wt} \%$ is $\mathrm{NaCl}$ (Kezia et al. 2015). The effect of low energy density ultrasound pulses and changes in temperature are investigated to shorten the induction time for precipitation and to enhance the solid recovery. The ability to selectively precipitate the calcium salts is also considered.

\section{Materials and Methods}

\subsection{Materials}

Purified water (a resistivity greater than $15.5 \mathrm{M} \Omega-\mathrm{cm}$, Millipore) is utilized for all experiments and cleaning processes. Buffer and standard solutions were prepared using double-purified water (resistivity greater than $18.2 \mathrm{M} \Omega-\mathrm{cm}$, Millipore). All chemical reagents utilized were analytical grade, isopropyl alcohol ( $\geq 99.7 \%)$ and sodium chloride $(\mathrm{NaCl},>99.5 \%)$ were purchased from Merck and tripotassium phosphate, $\mathrm{K}_{3} \mathrm{PO} 4(\geq 98 \%)$ was purchased from Sigma Aldrich. Lactose $((\geq 99.5 \%)$, calcium chloride dihydrate $\left(\mathrm{CaCl}_{2} .2 \mathrm{H}_{2} \mathrm{O},>99 \%\right)$ and disodium hydrogen phosphate $\left(\mathrm{Na}_{2} \mathrm{HPO}_{4},>99 \%\right)$ were purchased from Ajax Finechem.

The saline waste effluent was kindly supplied from a dairy factory in Victoria, Australia. The samples were labelled here as B1, B2, B3 and B4. The streams are derived from salty whey, which is the by- 
product from the production of various hard cheeses. Specifically, the samples were drawn from the permeate stream of an ultrafiltration unit used to recover saleable protein from the salty whey, and had a titratable acidity of $0.1-0.6 \mathrm{w} / \mathrm{v} \%(\mathrm{pH} 3.3-5)$. Upon arrival in our laboratory, the samples are refiltered using a $10 \mathrm{kDa}$ ultrafiltration membrane (Koch) for process standardisation, thus removing all residual protein. The effluent is then concentrated using membrane distillation at $50^{\circ} \mathrm{C}$ to either $22 \mathrm{wt} \%$ or $30 \mathrm{wt} \%$ total dissolved solids, according to a previously published procedure (Kezia et al. 2015). An independent concentration process was conducted for each crystallisation experiment and the concentrate was then transferred directly to the crystallisation chamber as soon as the final concentration was achieved. This was done to avoid any crystallisation lag time or the unmonitored formation of solid. The data in Table 1 thus represents the average result and the variation around this (one standard deviation of the data). As the protein was removed, the total organic content can be assumed to be predominantly the disaccharide lactose, with trace amounts of galactose and glucose. The mass ratio of relevant minerals in the solution is provided in Table 2.

Table 1. Composition of the saline effluent samples as received from the factory.

\begin{tabular}{llll}
\hline Sample labels & Total solid (\%) & Total ash (\%) & Total organic (\%) \\
\hline Batch 1 & $6.6 \pm 0.1$ & $4.9 \pm 0.3$ & $1.7 \pm 0.3$ \\
Batch 2 & $9.0 \pm 0.3$ & $7.4 \pm 0.1$ & $1.6 \pm 0.2$ \\
Batch 3 & $9.6 \pm 0.1$ & $7.4 \pm 0.6$ & $2.1 \pm 0.6$ \\
Batch 4 & $6.8 \pm 0.5$ & $5.4 \pm 0.4$ & $1.4 \pm 0.1$ \\
\hline
\end{tabular}

Concentration refers to total dissolved compound in wt \%

Table 2. Composition of the saline effluent samples after concentration using membrane distillation.

\begin{tabular}{llll}
\hline Sample labels & $\begin{array}{l}\text { Total dissolved } \\
\text { solids (\%) }\end{array}$ & Total ash (\%) & Total organics (\%) \\
\hline Batch 1 (22 wt\%) & $22.1 \pm 0.5$ & $16.5 \pm 0.9$ & $5.8 \pm 0.4$ \\
\hline Batch 1 (30 wt\%) & $30.3 \pm 1.9$ & $23.9 \pm 2.0$ & $6.4 \pm 0.2$ \\
Batch 2 & $30.1 \pm 0.6$ & $25.4 \pm 0.6$ & $4.7 \pm 0.7$ \\
\hline Batch 3 & $31.1 \pm 1.5$ & $24.3 \pm 1.4$ & $6.8 \pm 1.0$ \\
Batch 4 & $30.1 \pm 1.7$ & $24.0 \pm 0.6$ & $6.1 \pm 0.1$ \\
\hline
\end{tabular}


Table 3. Mass ratio of sodium ( $\mathrm{Na}$ ) and phosphorus $(\mathrm{P})$ relative to calcium (Ca)

\begin{tabular}{llll}
\hline Sample labels & Na & Ca & P \\
\hline Batch 1 (22 wt\%) & 12.6 & 1 & 0.43 \\
Batch 1 (30 wt\%) & 13.1 & 1 & 0.41 \\
Batch 2 & 26.5 & 1 & 0.46 \\
Batch 3 & 16.8 & 1 & 0.47 \\
Batch 4 & 26.3 & 1 & 0.65 \\
\hline
\end{tabular}

122

123

124

Some experiments were also conducted using simulated whey solutions. $\mathrm{CaCl}_{2} \cdot 2 \mathrm{H}_{2} \mathrm{O}(1,5$ and $10 \mathrm{mM})$ was mixed with $\mathrm{Na}_{2} \mathrm{HPO}_{4}(1,5$ and $10 \mathrm{mM})$ in a $1: 1 \mathrm{Ca} / \mathrm{P}$ ratio. The ionic strength was adjusted to 0 , 1.7M or $5.1 \mathrm{M}$ by adding $\mathrm{NaCl}$. Lactose ( 0 to $0.015 \mathrm{M}$ ) was also added in some cases.

\subsection{Methods}

The crystallisation of concentrated saline effluent was conducted in a $150 \mathrm{ml}$ cell with a double walled cooling jacket circulating an ethylene glycol solution to maintain constant temperature (Figure 1). All experiments were conducted using the same vessel and configuration as the liquid height can greatly affect the ultrasound intensity delivered to the liquid (Dong et al. 2012). A circulating temperature control bath (Julabo F12, FP50) was utilised to control temperature at $70^{\circ} \mathrm{C}$, $50^{\circ} \mathrm{C}$, and $10^{\circ} \mathrm{C}$. The cell was sealed tightly with Parafilm to avoid evaporation particularly at high temperatures. For all experiments, $100 \mathrm{~g}$ of concentrated saline effluent was introduced into the crystallisation cell directly from the membrane distillation feed tank. Constant stirring at $250 \mathrm{rpm}$ was applied using a magnetic stirrer. The stirring rate has been shown to enhance the mass transfer rate, which can affect the distribution of local supersaturation conditions (David 2001). To monitor the induction time, an online turbidity probe (H.E.L. Ltd) was utilised with the data recorded every minute. According to the manufacturer, the detection limit of this probe was a particle size of $0.5 \mu \mathrm{m}$. However, it should be noted that this detection limit may vary depending upon both the number of crystals formed and their morphology. The probe was calibrated to give a turbidity reading of 0.6 for pure water at all temperatures. The induction time was defined as the time elapsed between creation of supersaturation and the recording of a turbidity measurement above 
0.6 (Luque de Castro and Priego-Capote 2007). The pH was monitored throughout all experiments and remained within the range 3.3 to 5 .

Figure 1. Schematic diagram of the temperature controlled crystallisation chamber. $\mathrm{Cl}=$ turbidity indicator, $\mathrm{Tl}=$ temperature indicator.

A Digital sonifier (Branson Ultrasonic Corporation, Nominal Power $400 \mathrm{~W}$, frequency $20 \mathrm{kHz}$ ) was utilised, with the specified power calculated from the dial setting (\%) of $400 \mathrm{~W}$. The actual power supplied was measured using a power meter fixed to the instrument power supply (ARLEC), while the calorimetric power was determined by measurement of temperature increase. Linear trends were observed between the specified power, the power supplied and the calorimetric power as shown in Figure 2.

Figure 2. Calibration curve of specified power (the dial setting) versus calorimetric power and power supplied.

Ultrasound was applied as zero, one or two short pulses, from 3 to 20 seconds in duration (Figure 3 ) at 18,38 or $73 \pm 2$ Watt of power supplied. When two pulses were used, these were spaced ten minutes apart and delivered at identical power ( $73 \pm 2$ Watt), but for half the duration of a single pulse. The concentrate was then left to crystallize under constant temperature $\left(10,50\right.$ and $\left.70^{\circ} \mathrm{C}\right)$ and stirring conditions (250 rpm).

The ultrasonic energy density was determined from:

$$
\text { Energy Density }(J / g)=\frac{\text { Power supplied }(W) x \text { Pulse time }(s)}{\text { sample mass }(g)}
$$



pulses of ultrasound.

165

166

167

\subsection{Analysis}

The total dissolved solids content was determined by dry weight measurement after overnight evaporation at $110^{\circ} \mathrm{C}$, according to Australian Standard AS 2300.1.1. Total ash (inorganic solids) was measured after charring at $600^{\circ} \mathrm{C}$ overnight until samples turn white, as per Australian Standard AS 2300.1.5.

The concentration of $\mathrm{Na}, \mathrm{Ca}$ and $\mathrm{P}$ was measured using Inductively Coupled Plasma Optical Emission Spectrometry (Varian ICP-OES 720ES) on untreated samples rather than redissolved ash. The instrument detection limit is $0.01 \mu \mathrm{g} / \mathrm{L}$ for $\mathrm{Ca}, 0.15 \mu \mathrm{g} / \mathrm{L}$ for $\mathrm{Na}$ and $1.5 \mu \mathrm{g} / \mathrm{L}$ for $\mathrm{P}$. The samples were first diluted with purified water (18.2 M $2-\mathrm{cm}$, Millipore MilliQ) to obtain a sample within detection limits.

In some experiments, liquor samples were removed at the induction time. Liquor samples were also removed once crystallisation had ceased, that is, at least 12 hours after the turbidity had reached the maximum condition. Liquor samples were passed through a 0.2 micron membrane filter to recover the precipitated crystals and these were then washed three times with isopropyl alcoholwater (50:50) to remove the residual aqueous solution. The crystals were then dried and the crystal yield determined as:

$$
\text { Crystal yield }=\frac{\text { mass of dried crystals }}{\text { Total mass of sample }} \times 100 \%
$$

181 For imaging purposes, dried crystals were mounted onto aluminium stubs using carbon tabs. The 182 samples were gold coated using an Edwards S150B sputter coater and imaged using Field Emission Scanning Electron Microscopy (FESEM Philips XL30 FEG, 2 kV beam). The crystalline particle size distribution was also determined using laser diffraction (Malvern Mastersizer 2000, Malvern 
Instruments Ltd, Malvern, UK). Isopropyl alcohol-water (50:50) was used as the dispersant and strong agitation was applied to break the aggregates. The Mastersizer stirring speed applied was $1000 \mathrm{rpm}$ and the circulating pump speed was $2500 \mathrm{rpm}$. The refractive index of the crystalline salts was 1.6 and that of the isopropyl alcohol-water (50:50) was 1.36 (Chu and Thompson 1962). Data reported is the average of three measurements. The crystal structure was determined using powder x-ray diffraction (XRD) (Bruker,D8 Advance Diffractometer).

\section{Results and discussion}

\subsection{Induction time}

As could be anticipated (Ho and Zydney 2000), the crystallisation induction time can be significantly shortened from 13 hours down to 3 hours at $50^{\circ} \mathrm{C}$ and from 3.2 hours to 1.7 hours at $70^{\circ} \mathrm{C}$ by increasing the initial dissolved solids concentration, and thus the degree of supersaturation, from 22 $\mathrm{w} / \mathrm{t} \%$ to $30 \mathrm{w} / \mathrm{t} \%$ (Figure 4). However, the use of lower initial concentrations is appealing as it avoids fouling in the upstream concentration process and reduces the energy required in this first step.

Figure 4. Induction time with respect to temperature at 22 and $30 \mathrm{wt} \%$ initial dissolved solids concentration (Sample B1). Error bars are based on replicate crystallisation experiments and so indicate the variability in this induction time.

A substantial reduction of induction time is observed with increasing temperature for both initial salt concentrations. This is the opposite trend to that commonly observed for sugars and for chloride salts, where the solubility generally increases with increasing temperature. The variability in the induction time also reduces as the temperature increases. Although the predominant salt in the waste stream is $\mathrm{NaCl}$, this trend reflects the behaviour of calcium phosphate, as the less soluble salt. 
to form a range of intermediate phases prior to forming the most stable crystal morphology as the final product. In particular, the formation of HAP (hydroxyapatite, with the lowest solubility) can be preceded by OCP (octacalcium phosphate, $\mathrm{Ca}_{4} \mathrm{H}_{(}\left(\mathrm{PO}_{4}\right)_{3}$ ) and DCPD (dicalcium phosphate dihydrate, $\mathrm{CaHPO}_{4} \cdot 2 \mathrm{H}_{2} \mathrm{O}$ ) (Chow and Eanes 2001). Both HAP and OCP are known to exhibit reverse solubility behaviour above $15-20^{\circ} \mathrm{C}$. In contrast, the solubility of DCPD in fact increases slightly with increasing temperature (Green and Perry 2007). DCPA (anhydrous dicalcium phosphate) can precipitate at higher temperatures (Miyazaki et al. 2009). In a mixture, nucleation could occur even if there is sufficient driving force for only one component (Mullin 2001). Thus, nucleation of one intermediate type of calcium phosphate could then be followed with the dominant form. Thus, the bulk precipitation may be initiated by the precipitation of OCP, followed by DCPD and DCPA as the dominant calcium phosphate forms in the acidic environment ( $\mathrm{pH} 2-6)$ (Dorozhkin 2014). Alternatively, the results may reflect an increasing rate of calcium phosphate crystallisation with increasing temperature, independent of any thermodynamic effects.

Figure 5 shows that the cavitation generated through the application of ultrasound at $7.3 \mathrm{~J} / \mathrm{g}$ can shorten the induction time further for $30 \mathrm{wt} \%$ dissolved solids across the full temperature range tested. For example, the induction time decreased from approximately 1.7 hours to approximately 0.3 hours at $70^{\circ} \mathrm{C}$ and from approximately 2.6 hours to approximately 1.1 hours at $50^{\circ} \mathrm{C}$. Luque de Castro and Priego-Capote (2007) reported similar effects for roxithromycin and (Lyczko et al. 2002) also observed a faster induction time using a simulated solution of potassium sulfate. These effects probably reflect bubbles generated in the solution acting as a foreign surface to facilitate heterogeneous crystallisation. At the low ultrasonic frequency used $(20 \mathrm{kHz})$, the bubble collapse is also intense and provides extra energy to overcome the nucleation energy barrier.

Figure 5. Induction time with respect to temperature conducted with and without a single initial pulse of ultrasound of 73 Watts, of duration from 0 to 10 seconds( 0 to $15 \mathrm{~J} / \mathrm{g}$ energy density) at constant stirring (samples B1 and B2 with initial dissolved solids $30 \mathrm{wt} \%$ ). 
The effect of ultrasound was also assessed as a function of temperature. Gogate et al. (2003) shows that the acoustic bubble collapse pressure decreases linearly with increasing temperature which may result in a more pronunced ultrasound effect at lower temperature. Entezari and Kruus (1996) also show a decrease of cavitation intensity at higher temperature. However, there is no evidence of a greater effect at lower temperatures within the range of acoustic energy densities investigated in this study. With increasing temperature, the properties of the working solution such as viscosity, density and supersaturation ratio are altered, which might disguise any effect of ultrasound with respect to temperature.

To investigate the effect of ultrasound further, additional experiments were conducted where the energy density and the concentration of solid were varied at $15 \mathrm{~J} / \mathrm{g}$ and $22 \mathrm{wt} \%$ respectively. These experiments were conducted at $50^{\circ} \mathrm{C}$, as this is the temperature used in the earlier concentration process (membrane distillation) and hence the effects of cooling and heating could be minimised. The effect of ultrasound is more pronounced at $22 \mathrm{wt} \%$ total dissolved solids, falling from 12 to 1.5 hours when $15 \mathrm{~J} / \mathrm{g}$ ultrasound is applied (Figure 5). This reflects the lower degree of supersaturation at $22 \mathrm{wt} \%$ solids. Increasing the energy density from 3.7 to $15 \mathrm{~J} / \mathrm{g}$ by increasing the pulse time at constant power has no effect in altering the induction time (Figures 5 and 6 ). This shows that beyond a critical time period, increasing the length of insonation merely escalates the energy consumption. On the contrary, increasing the power applied, while shortening the duration of insonation to maintain a constant energy density of $8 \mathrm{~J} / \mathrm{g}$ has a very significant effect (Figure 7 ). The induction time falls from 3.3 hours down to 1.7 hours when the power is increased from 18 to 75 Watt. This result agrees with the work of (Dincer et al. 2014), who observed a 40\% reduction in induction time for a lactose solution when a six fold increase in power was applied. Kordylla et al. (2008) also claims that the power supplied determines the formation of the first nuclei. constant stirring (samples B1 and B2 with initial dissolved solids $30 \mathrm{wt} \%, 50 \mathrm{oC}$ ). 
Figure 7. Induction time with respect to power level at a constant energy density of $8 \mathrm{~J} / \mathrm{g}$. The large error bars reflect the use of two different batches of feed (samples B3 and B4 with initial dissolved solids $30 \mathrm{wt} \%, 50 \circ \mathrm{C})$.

The effect of a second pulse of ultrasound two hours after the first has been shown in other work to restimulate the growth of nuclei during lactose crystallisation (Henglein 1995, Zisu et al. 2014). In this case, the use of a second short pulse of ultrasound, ten minutes after the first, had a significant effect on the induction time (Figure 8). It is shown that, at $50^{\circ} \mathrm{C}$ and a total energy density of 7.3 and $15 \mathrm{~J} / \mathrm{g}$, the induction time was reduced from 1.2 hours to 0.8 hours. Similarly, at $10^{\circ} \mathrm{C}$, the induction time reduced from $15.3 \pm 0.9$ hours to $12.3 \pm 3.1$ hours at all energy densities. At $3.7 \mathrm{~J} / \mathrm{g}$ and $50^{\circ} \mathrm{C}$, the data for the single and double pulse cases converged, perhaps suggesting that this is the minimum energy threshold required for the ultrasound to be effective. Alternatively, it may be related to experimental error, as the pulsation time is only $2 \mathrm{~s}$ under these conditions. We believe that this is the first time that it has been shown that the use of two ultrasound pulses during the induction period can reduce the total induction time, relative to a single pulse of the same duration. The only other work that utilised two pulses employed the second pulse after crystallisation had commenced(Zisu et al. 2014).

Figure 8. Induction time for single and double pulse application. The energy quoted is the total supplied across both pulses when two pulses are used (samples B2 and B3 with initial dissolved solids 30 wt\%).

\subsection{Crystal Size and Morphology}

Figure 9 shows the final crystal size distribution as recorded using laser diffraction. However, it should be noted that some of the crystal sizes shown here actually represent the size of crystal aggregates (Figure 10). Analysis of images such as Figure 10 indicate that the cubic $\mathrm{NaCl}$ crystals are 
typically 10-12 micron in size, with the calcium phosphate crystals significantly smaller. Neither the power supplied, the time of insonation (data not shown), or the energy density had a significant effect on the final crystal size distribution when a single ultrasound pulse was used (Figure 9a). In the present case, the ultrasound is applied only before crystals can be detected using the turbidity probe. Indeed, crystals are not observed until minutes after the ultrasound is disabled. Thus, in this case sonication is acting either to generate new nuclei or to enhance the mass transfer of solute toward the surface of sub-micron growing crystals. In prior work, sonication has been shown to break down crystals and crystal aggregates due to microturbulence, shockwaves and collisions (Nalajala and Moholkar 2011, Sander et al. 2014, Wagterveld 2013), but this is less likely to occur here due to the early application of the acoustic pulse.

Figure 9. Particle size distribution of the solids recovered once crystallisation had ceased (samples B2 and B3 with initial dissolved solids $30 \mathrm{wt} \%$ ). Single pulse data (a), comparison of single and double

$$
\text { pulse results (b). }
$$

Figure 10. SEM image of the solids recovered once crystallisation had ceased, showing the formation of crystal aggregates and the differing size of the cubic $\mathrm{NaCl}$ crystals and the smaller calcium

$$
\text { phosphate crystals. }
$$

A consistent trend in particle size with respect to temperature cannot be observed (data not shown). This may reflect the fact that while the concentration of calcium phosphate determines the induction time, the predominant crystals at the end of the crystallisation process are sodium chloride (see Section 3.3 below) and the saturation conditions for this salt are relatively independent of temperature (Green and Perry 2007).

Conversely, the use of a second ultrasound pulse results in an obvious reduction in the particle size, with a shoulder appearing in the smallest size range (Figure 9b). If the initial ultrasound burst induces primary nuclei to form, the second pulse may disrupt the growing nuclei creating secondary 
nuclei, which in turn generates greater crystal surface area and thus a more rapid induction time. The particle size reduction can be achieved with a total energy input less than the energy input of the single pulse.

The morphology of the calcium phosphate precipitated in the early stages of crystallisation are portrayed in Figure 11. These samples were taken as the turbidity is first increasing, rather than when the system had reached the maximum turbidity condition. They are for crystallisation at $50^{\circ} \mathrm{C}$ to minimize the contribution of cooling or heating on the system after membrane distillation. In these early stages of crystallisation, calcium phosphate dominates with fewer of the cubic $\mathrm{NaCl}$ crystals than observed in Figure 10. The "flake", "plate" and "agglomerated" shapes of these minerals have been reported by several researchers (Chow and Eanes 2001, Koutsoukos et al. 1980) and are expected to correspond respectively to the structures of dicalcium phosphate, in its dihydrate (DCPD, $\left.\mathrm{CaHPO}_{4} .2 \mathrm{H}_{2} \mathrm{O}\right)$ and anhydrous $\left(\mathrm{DCPA}, \mathrm{CaHPO}_{4}\right)$ form, and octacalcium phosphate $\left(\mathrm{Ca}_{4} \mathrm{H}\left(\mathrm{PO}_{4}\right)_{3}\right.$ or $\left.\mathrm{OCP}\right)$. In this case, differences in crystal morphology with the application of ultrasound were not expected, as the acoustic frequency was low and constant at $20 \mathrm{kHz}$. While low frequencies deliver high cavitation intensity due to more forceful bubble collapse phenomena, previous work has shown little effect on the morphology of simple calcium salts (calcium sulfate (Davies et al. 2015) and calcium carbonate (Nishida 2004)). In contrast, (Su et al. 2015) observed a morphology change during sonocrystallisation of calcium carbonate from seawater. Interestingly, in the present work a "needle" shaped crystal is observed in the sonicated sample (Figure $11 \mathrm{e}, \mathrm{f}$ ), while none is observed in the non-sonicated one. This was observed even though the same batch (B2) of sample was used to maintain a consistent ratio of other salts such as $\mathrm{NaCl}$ and lactose, as well as organic anions such as citrate and lactate. The changes in morphology may relate to the localized increases in temperature and pressure in the vicinity of individual cavitation bubbles. Chen et al. (2011) has shown that changes in absolute pressure can result in different crystal morphologies for hydroxyapatite (HAP). 
Figure 11. The morphology of crystals sampled shortly after the induction time for experiments conducted without ultrasound $(a, b, c, d$, samples taken at $t=2.9 \mathrm{hrs})$ and with a single pulse of ultrasound at $7.3 \mathrm{~J} / \mathrm{g}\left(\mathrm{e}, \mathrm{f}\right.$, samples taken at 1.2 hours) at $50^{\circ} \mathrm{C}$ (sample $\mathrm{B} 2$ with initial dissolved solids $30 \mathrm{wt} \%)$. The circles show the areas of 'needle like' crystals in the sonicated samples.

To confirm this result, experiments were conducted with simulated whey solutions as described in Section 2.1. In these simple systems, containing calcium phosphate, $\mathrm{NaCl}$ and lactose only, no alteration in crystal morphology was observed when ultrasound was applied. In a real dairy system the presence of ultrasound might influence other minor components such as soluble casein and organic anions, which in turn might result in the observed changes in crystal morphology, or in the crystallisation of other species. Further work is required to separate the role of impurities versus the role of ultrasound in dictating the precipitation of calcium phosphate.

While lactose is the second most abundant species in the effluent, no lactose precipitate was detected, as the lactose is not supersaturated (Green and Perry 2007, Jensen et al. 1940).

Presented in Figure 12 is XRD spectra of the precipitate after reaching the maximum turbidity condition. Despite the induction period being governed by the calcium phosphate salts, selective precipitation could not be achieved. The dominating salt, $\mathrm{NaCl}$, starts to crystalize as soon as solid templates are formed. It can be seen that the spectra is dominated by the intensity of these $\mathrm{NaCl}$ peaks. At the higher temperature of $70^{\circ} \mathrm{C}$ where the saturation of calcium phosphate is at a maximum, the remaining peaks might correspond to the calcium-phosphate minerals. However, accurate determination of the calcium phosphate crystal morphology could not be justified since the intensity of these peaks is very low. A further fundamental study using simulated model solutions is required to deepen our understanding of this crystal morphology and this is planned for our future work. 

conducted at room temperature $\pm 22 \mathrm{oC}$ (Sample B2 and B3).

\subsection{Crystal Yield}

Another important variable is the quantity of crystalline solid recovered or the crystal yield. This is very low at $\pm 3 \%$ (at the equilibrium condition) when the total dissolved solids concentration is initially $30 \mathrm{wt} \%$. Bund et al. show increasing lactose recovery with sonication, both in experiments with reconstituted lactose solutions (Bund and Pandit 2007a) and in experiments where ethanol was used to increase the supersaturation levels of paneer whey (Bund et al. 2007). Nevertheless, this behaviour is not observed in this current study - while ultrasound reduced the time required to achieve the final yield, this final crystal yield remained at $3 \%$. A similar trend is observed by (Zisu et al. 2014) where the crystal yield was governed only by the solubility limit and supersaturation level. Further direct evaporation is necessary in order to recover a higher equilibrium yield and to reduce the amount of liquid saline waste requiring disposal.

\section{4. $\underline{\text { Conclusion }}$}

Crystallisation of concentrated saline dairy effluent consisting of a mixture of calcium phosphate, $\mathrm{NaCl}$ and sugars has been investigated. As expected, with higher initial concentration $(30 \%$ total dissolved solids versus $22 \%$ ), the induction time can be significantly shortened from approximately 12 hours to 3 hours at $50^{\circ} \mathrm{C}$ and from 3.2 hours to 1.7 hours at $70^{\circ} \mathrm{C}$. Reverse solubility behaviour is observed where the induction time falls as temperature increases, indicating the importance of calcium phosphate regardless of the fact that $\mathrm{NaCl}$ presents as the dominating salt. A single pulse of ultrasound can reduce this induction time further, but neither the length of this pulse or the operating temperature has significant influence on the extent of the reduction. Conversely, increasing the acoustic power of the pulse has a significant impact, even when the same energy 
density is applied. The use of two separate pulses of ultrasound spaced ten minutes apart also results in a significantly reduced induction time. During the interval between the pulses, growth of the crystal nuclei occurs and the second pulse may disrupt these growing crystals, creating smaller crystal templates. This is reflected in the crystal size distribution. The calcium phosphate crystals exhibit a range of crystal morphologies. In particular, needle like crystals are observed exclusively in the presence of ultrasound, possibly as a result of transient increases in local pressure.

While calcium phosphate dictates the induction time, it was not possible to selectively precipitate this salt due to the large quantities of $\mathrm{NaCl}$ also present. Further, for both sonicated and noninsonated solutions, the solid recovery is limited at $\pm 3 \%$. The recovery can only be improved by increasing the supersaturation level, hence further evaporation is necessary to achieve realistic crystal yields.

\section{Acknowledgements}

The supply of salty whey from an Australian dairy company is gratefully acknowledged. Funding from the Dairy Innovation Research Hub, an Industrial Transformation Research Hub(IH120100005) of the Australian Research Council is also acknowledged. Judy Lee acknowledges the support from an Australian Research Council Discovery Early Career Researcher Award (DE120101567).

\section{References}

Amjad, Z. (2013) Calcium Phosphates in Biological and Industrial Systems, Springer US. Blaschek, K.M., Wendorff, W.L. and Rankin, S.A. (2007) Survey of salty and sweet whey composition from various cheese plants in Wisconsin. Journal of Dairy Science 90(4), 2029 - 2034.

400 Bund, R., Bund, A. and Pandit (2007) Rapid lactose recovery from paneer whey using 401 sonocrystallization: A process optimization. Chemical engineering and processing 46(9), 846-850.

402 Bund, R. and Pandit, A. (2007a) Sonocrystallization: effect on lactose recovery and crystal habit. 403 Ultrasonics sonochemistry 14(2), 143-152.

404 Bund, R.K. and Pandit, A.B. (2007b) Rapid lactose recovery from buffalo whey by use of 'anti-solvent, 405 
406 Chen, C., Huang, Z., Yuan, W., Li, J., Cheng, X. and Chi, R.-a. (2011) Pressure effecting on morphology of hydroxyapatite crystals in homogeneous system. CrystEngComm 13(5), 1632-1637.

408 Chow, L.C. and Eanes, E.D. (2001) Octacalcium Phosphate, Monographs in Oral Science, Vol. 18 Karger, Basel, Switzerland.

Chu, K.-Y. and Thompson, A.R. (1962) Densities and Refractive Indices of Alcohol-Water Solutions of n-Propyl, Isopropyl, and Methyl Alcohols. Journal of Chemical \& Engineering Data 7(3), 358-360.

David, R. (2001) General rules for prediction of the intensity of micromixing effects on precipitations.

413 Powder Technology 121(1), 2-8.

Davies, L.A., Dargue, A., Dean, J.R. and Deary, M.E. (2015) Use of $24 \mathrm{kHz}$ ultrasound to improve sulfate precipitation from wastewater. Ultrasonics Sonochemistry 23, 424-431.

Dincer, T., Zisu, B., Vallet, C., Jayasena, V., Palmer, M. and Weeks, M. (2014) Sonocrystallisation of lactose in an aqueous system. International Dairy Journal 35(1), 43-48.

Dong, H.X., Yang, X.G., Yue, G.J., Tang, J.Y., Lv, Y. and Liu, W.X. (2012) Impact of Immersion Depth of Ultrasonic Horn on Acoustic Field Distribution Using Thermoelectric Probe, Advanced Materials Research Conference, Trans Tech Publ. Vol. 455 pp. 65-68,

Dorozhkin, S. (2014) Calcium Orthophosphates: Occurrence, Properties and Major Applications. Bioceram Dev Appl 4(081), 2.

Entezari, M.H. and Kruus, P. (1996) Effect of frequency on sonochemical reactions II. Temperature and intensity effects. Ultrasonics Sonochemistry 3(1), 19-24.

Gogate, P.R., Wilhelm, A.M. and Pandit, A.B. (2003) Some aspects of the design of sonochemical reactors. Ultrasonics Sonochemistry 10(6), 325-330.

Green, D. and Perry, R. (2007) Perry's Chemical Engineers' Handbook, Eighth Edition, McGraw-Hill Education.

Henglein, A. (1995) Chemical effects of continuous and pulsed ultrasound in aqueous solutions. Ultrasonics sonochemistry 2(2), S115-S121.

Ho, C.-C. and Zydney, A.L. (2000) A combined pore blockage and cake filtration model for protein fouling during microfiltration. Journal of Colloid and Interface Science 232(2), 389-399.

Kezia, K., Lee, J., Weeks, M. and Kentish, S. (2015) Direct contact membrane distillation for the concentration of saline dairy effluent. Water Research 81, 167-177

Kordylla, A., Koch, S., Tumakaka, F. and Schembecker, G. (2008) Towards an optimized crystallization with ultrasound: Effect of solvent properties and ultrasonic process parameters. Journal of Crystal Growth 310(18), 4177-4184.

Kougoulos, E., Marziano, I. and Miller, P. (2010) Lactose particle engineering: Influence of ultrasound and anti-solvent on crystal habit and particle size. Journal of Crystal Growth 312(23), 3509-3520.

$443 \mathrm{Li}, \mathrm{H} ., \mathrm{Li}, \mathrm{H} ., \mathrm{Guo}, \mathrm{Z}$. and Liu, Y. (2006) The application of power ultrasound to reaction crystallization.

Koutsoukos, P., Amjad, Z., Tomson, M. and Nancollas, G. (1980) Crystallization of calcium phosphates. A constant composition study. Journal of the American Chemical Society 102(5), 15531557. Ultrasonics Sonochemistry 13(4), 359-363. process. Journal of Crystal Growth 247(1), 192-198. 
Lyczko, N., Espitalier, F., Louisnard, O. and Schwartzentruber, J. (2002) Effect of ultrasound on the 450 induction time and the metastable zone widths of potassium sulphate. Chemical Engineering Journal 451 86(3), 233-241.

452 Miyazaki, T., Sivaprakasam, K., Tantry, J. and Suryanarayanan, R. (2009) Physical characterization of 453 dibasic calcium phosphate dihydrate and anhydrate. Journal of Pharmaceutical Sciences 98(3), 905454916.

Mullin, J.W. (2001) Crystallization. 4th Ed, Oxford: Butterworth-Heinemann.

Nalajala, V.S. and Moholkar, V.S. (2011) Investigations in the physical mechanism of sonocrystallization. Ultrasonics Sonochemistry 18(1), 345-355.

458 Nishida, I. (2004) Precipitation of calcium carbonate by ultrasonic irradiation. Ultrasonics 459 Sonochemistry 11(6), 423-428.

460 Rice, G., Barber, A., O'Connor, A., Stevens, G.W. and Kentish, S.E. (2009a) Fouling of NF membrane 461 by dairy ultrafiltration permeate. Journal of Membrane Science 330, 117-126.

462 Rice, G., Kentish, S.E., O'Connor, A., Barber, A., Philajamaki, A., Nystrom, M. and Stevens, G.W. 463 (2009b) Analysis of separation and fouling behaviour during nanofiltration of dairy ultrafiltration 464 permeate. Desalination 236, 23-29.

465 Ruecroft, G., Ruecroft, D., Hipkiss, T., Ly, N., Maxted, P. and Cains (2005) Sonocrystallization: The 466 Use of Ultrasound for Improved Industrial Crystallization. Organic process research \& development $4679(6), 923-932$.

468 Sander, J.R., Zeiger, B.W. and Suslick, K.S. (2014) Sonocrystallization and sonofragmentation. 469 Ultrasonics Sonochemistry 21(6), 1908-1915.

470 Schäfer, A., Fane, A.G. and Waite, T. (1998) Nanofiltration of natural organic matter: removal, fouling 471 and the influence of multivalent ions. Desalination 118(1), 109-122.

472 Su, M., Han, J., Li, Y., Chen, J., Zhao, Y. and Chadwick, K. (2015) Ultrasonic Crystallization of Calcium 473 Carbonate in Presence of Seawater lons. Desalination 369, 85-90.

474 Wagterveld, R.M. (2013) Effect of Ultrasound on Calcium Carbonate Crystallization, PhD Thesis, Delft 475 University of Technology, Delft, The Netherlands.

476 Wohlgemuth, K., Ruether, F. and Schembecker, G. (2010) Sonocrystallization and crystallization with 477 gassing of adipic acid. Chemical Engineering Science 65(2), 1016-1027.

478 Yu, Z.Q., Chew, J.W., Chow, P.S. and Tan, R.B.H. (2007) Recent Advances in Crystallization control: An 479 Industrial Perspective. Chemical Engineering Research and Design 85(7), 893-905.

480 Zamanipoor, M.H. and Mancera, R.L. (2014) The emerging application of ultrasound in lactose 481 crystallisation. Trends in Food Science \& Technology 38(1), 47-59.

482 Zisu, B., Sciberras, M., Jayasena, V., Weeks, M., Palmer, M. and Dincer, T.D. (2014) 483 Sonocrystallisation of lactose in concentrated whey. Ultrasonics Sonochemistry 21(6), 2117-2121. 
Table 1. Composition of the saline effluent samples as received from the factory.

Table 2. Composition of the saline effluent samples after concentration using membrane distillation.

Table 3. Mass ratio of sodium ( $\mathrm{Na}$ ) and phosphorus $(\mathrm{P})$ relative to calcium $(\mathrm{Ca})$ within the saline waste effluent after concentration using membrane distillation.

\section{Figure captions}

Figure 1. Schematic diagram of the temperature controlled crystallisation chamber. $\mathrm{Cl}=$ turbidity indicator, $\mathrm{Tl}=$ temperature indicator.

Figure 2. Calibration curve of specified power (the dial setting) versus calorimetric power and power supplied.

Figure 3. Schematic diagram of the experimental procedure for application of single and double pulses of ultrasound.

Figure 4. Induction time with respect to temperature at 22 and $30 \mathrm{wt} \%$ initial dissolved solids concentration (Sample B1). Error bars are based on replicate crystallisation experiments and so indicate the variability in this induction time.

Figure 5. Induction time with respect to temperature conducted with and without a single initial pulse of ultrasound of 73 Watts, of duration from 0 to 10 seconds( 0 to $15 \mathrm{~J} / \mathrm{g}$ energy density) at constant stirring (samples B1 and B2 with initial dissolved solids 30 wt\%).

Figure 6. Turbidity measurement for experiments conducted with a single pulse of ultrasound at constant stirring (samples B1 and B2 with initial dissolved solids $30 \mathrm{wt} \%, 50^{\circ} \mathrm{C}$ ).

Figure 7. Induction time with respect to power level at a constant energy density of $8 \mathrm{~J} / \mathrm{g}$. The large error bars reflect the use of two different batches of feed (samples B3 and B4 with initial dissolved solids 30 wt $\%, 50^{\circ} \mathrm{C}$ ).

Figure 8. Induction time for single and double pulse application. The energy quoted is the total supplied across both pulses when two pulses are used (samples B2 and B3 with initial dissolved solids $30 \mathrm{wt} \%)$.

Figure 9. Particle size distribution of the solids recovered once crystallisation had ceased (samples B2 and B3 with initial dissolved solids 30 wt\%). Single pulse data (a), comparison of single and double pulse results (b).

Figure 10. SEM image of the solids recovered once crystallisation had ceased, showing the formation of crystal aggregates and the differing size of the cubic $\mathrm{NaCl}$ crystals and the smaller calcium phosphate crystals.

Figure 11. The morphology of crystals sampled shortly after the induction time for experiments conducted without ultrasound $(a, b, c, d$, samples taken at $t=2.9 \mathrm{hrs})$ and with a single pulse of 
521 ultrasound at $7.3 \mathrm{~J} / \mathrm{g}$ (e, f, samples taken at 1.2 hours) at $50^{\circ} \mathrm{C}$ (sample B2 with initial dissolved solids $52230 \mathrm{wt} \%)$. The circles show the areas of 'needle like' crystals in the sonicated samples.

523 Figure 12. X-ray diffraction pattern of crystals recovered from precipitation, experiment was

524 conducted at room temperature $\pm 22^{\circ} \mathrm{C}$ (Sample B2 and B3).

525

526 


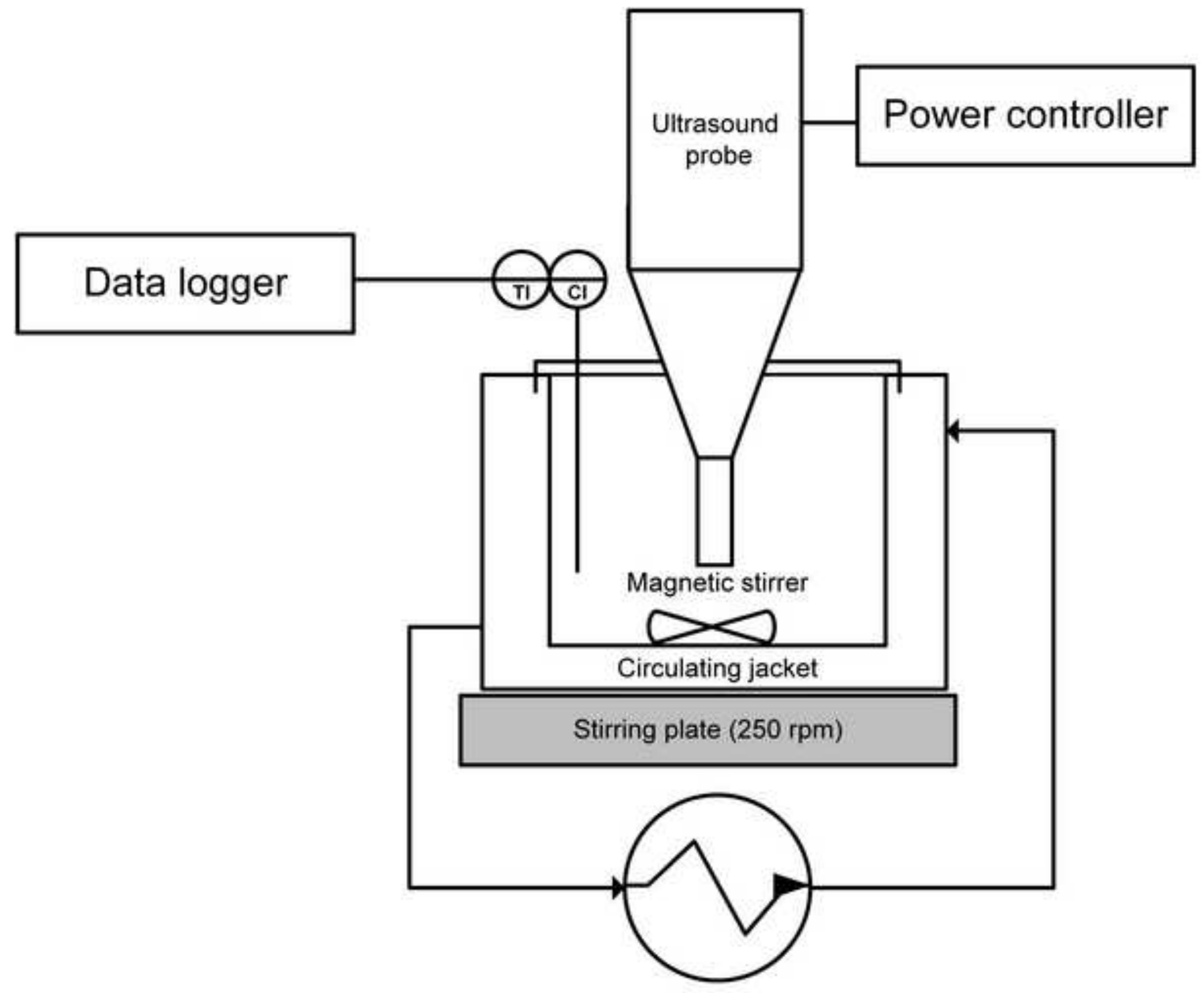


Figure 2

Click here to download high resolution image

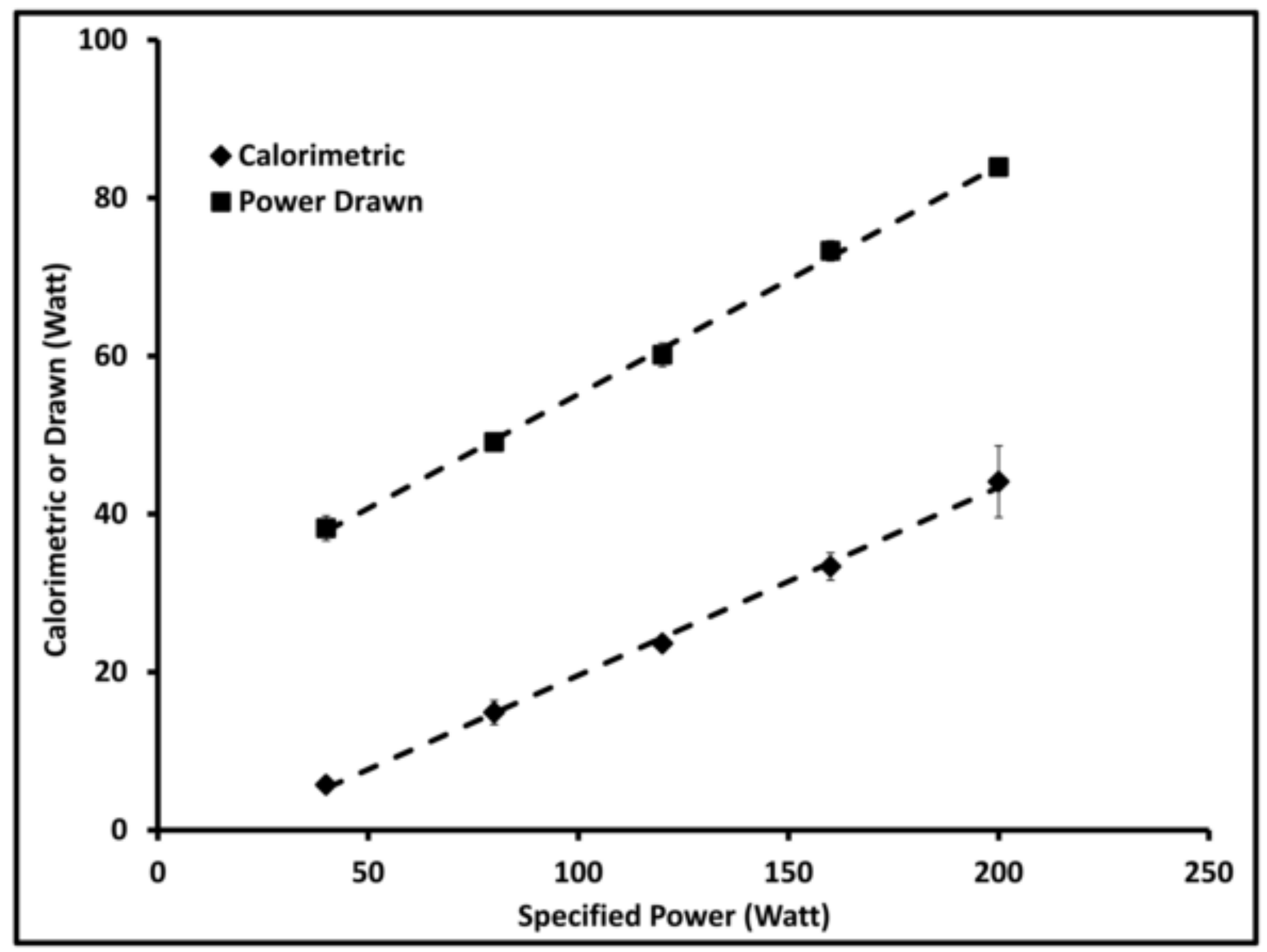




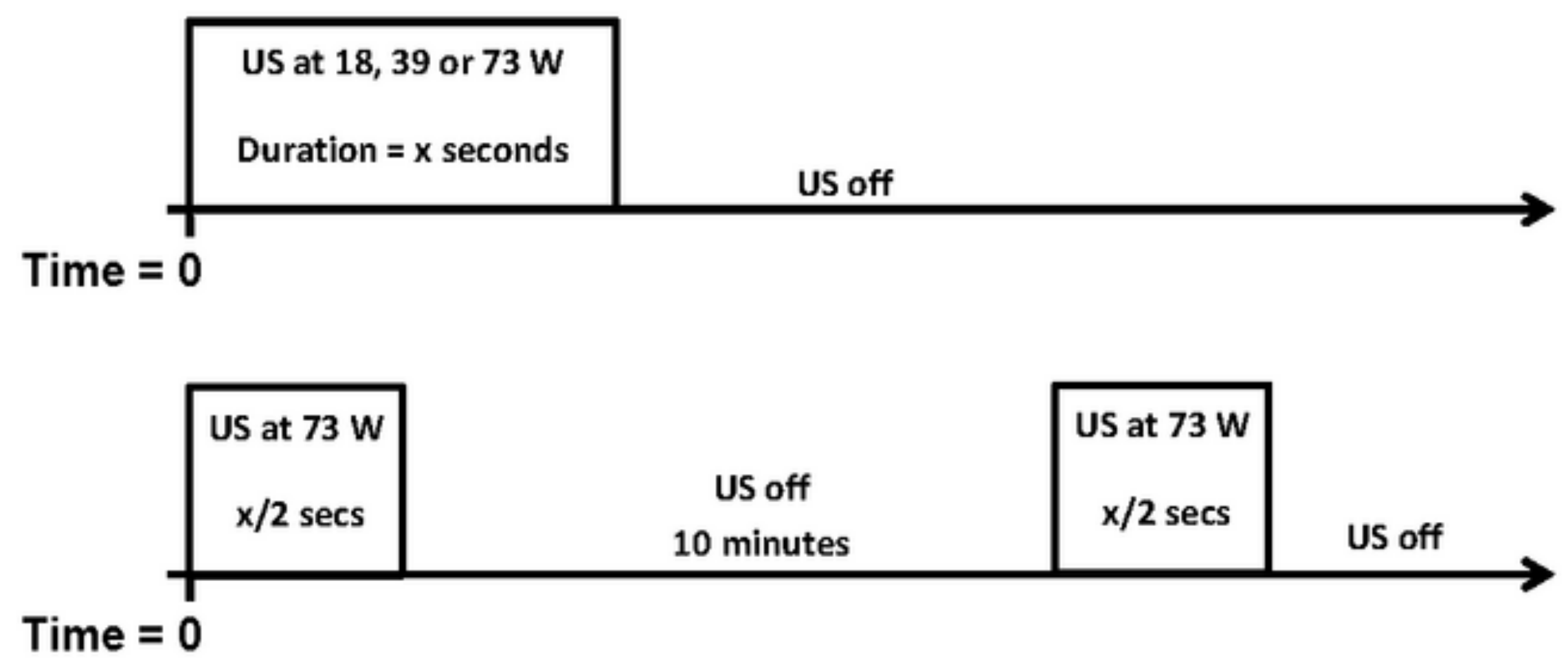

Time $=0$

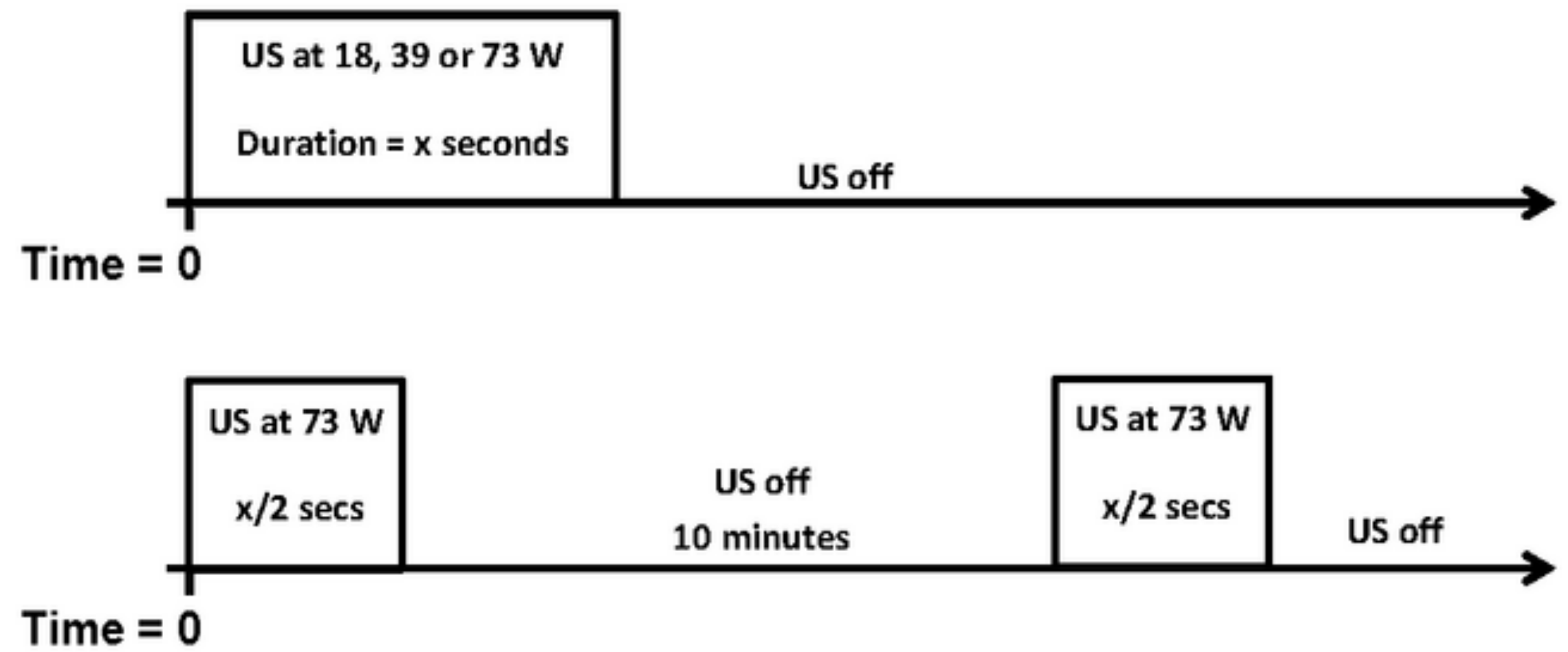

Time $=0$ 


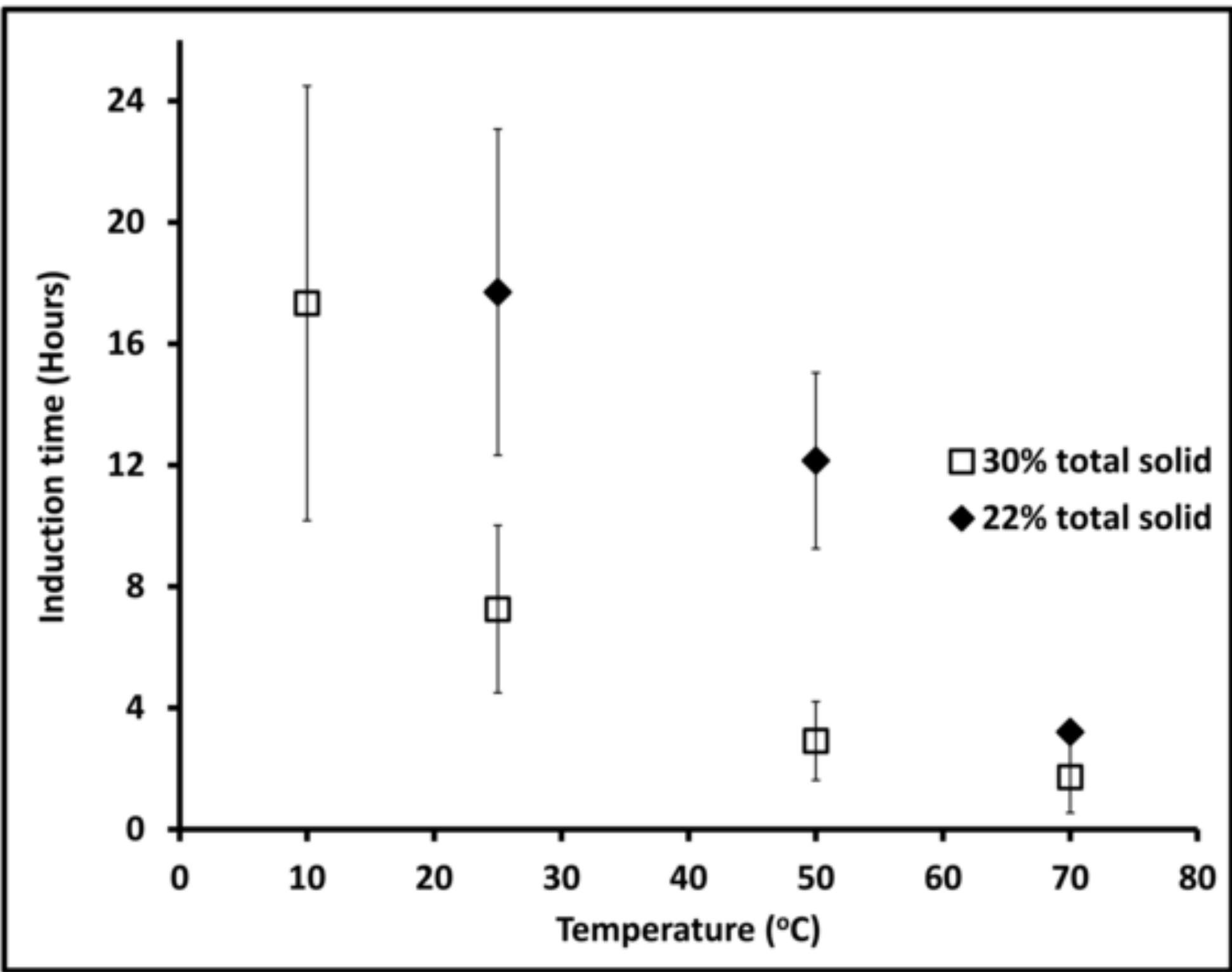




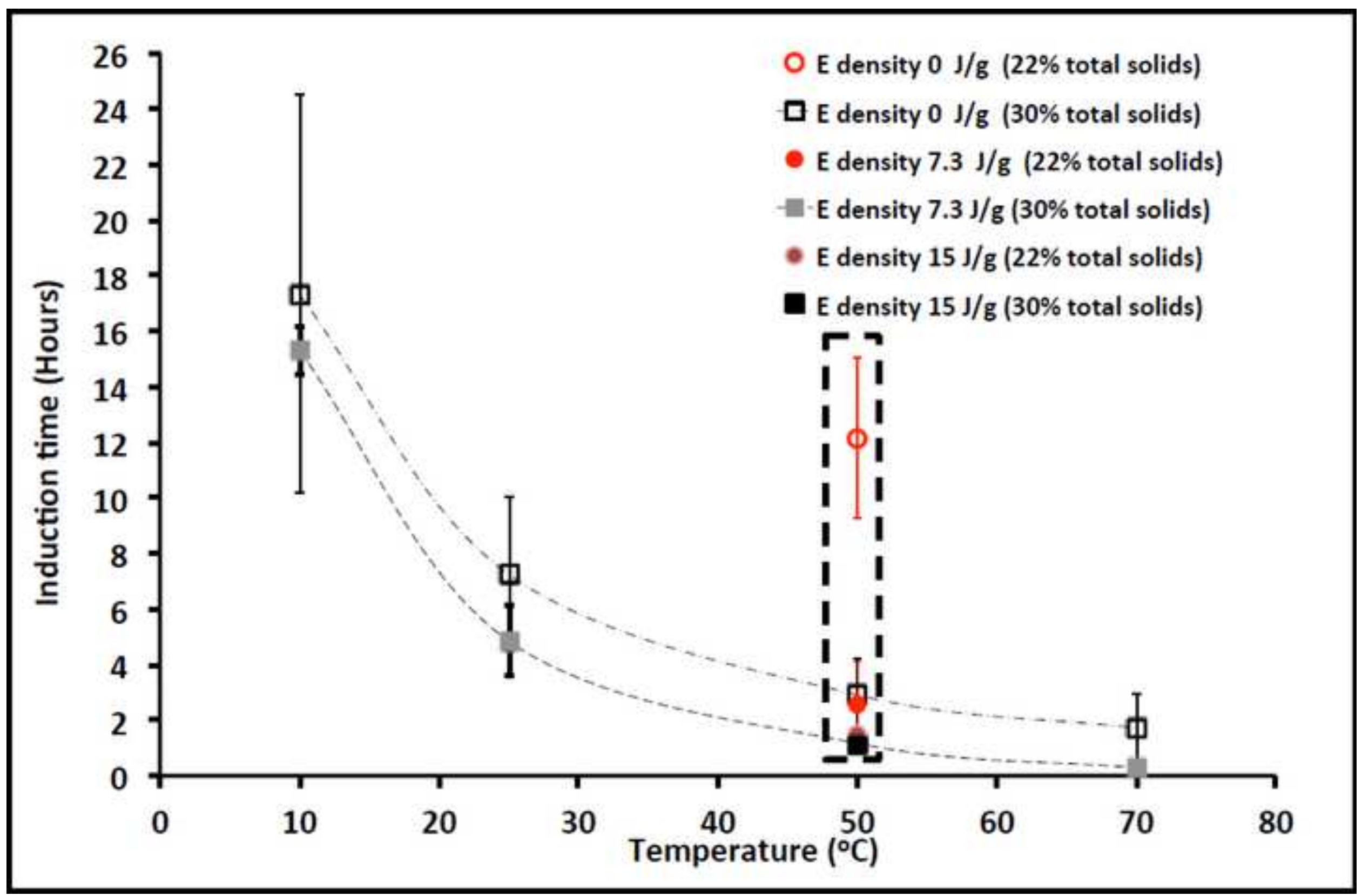




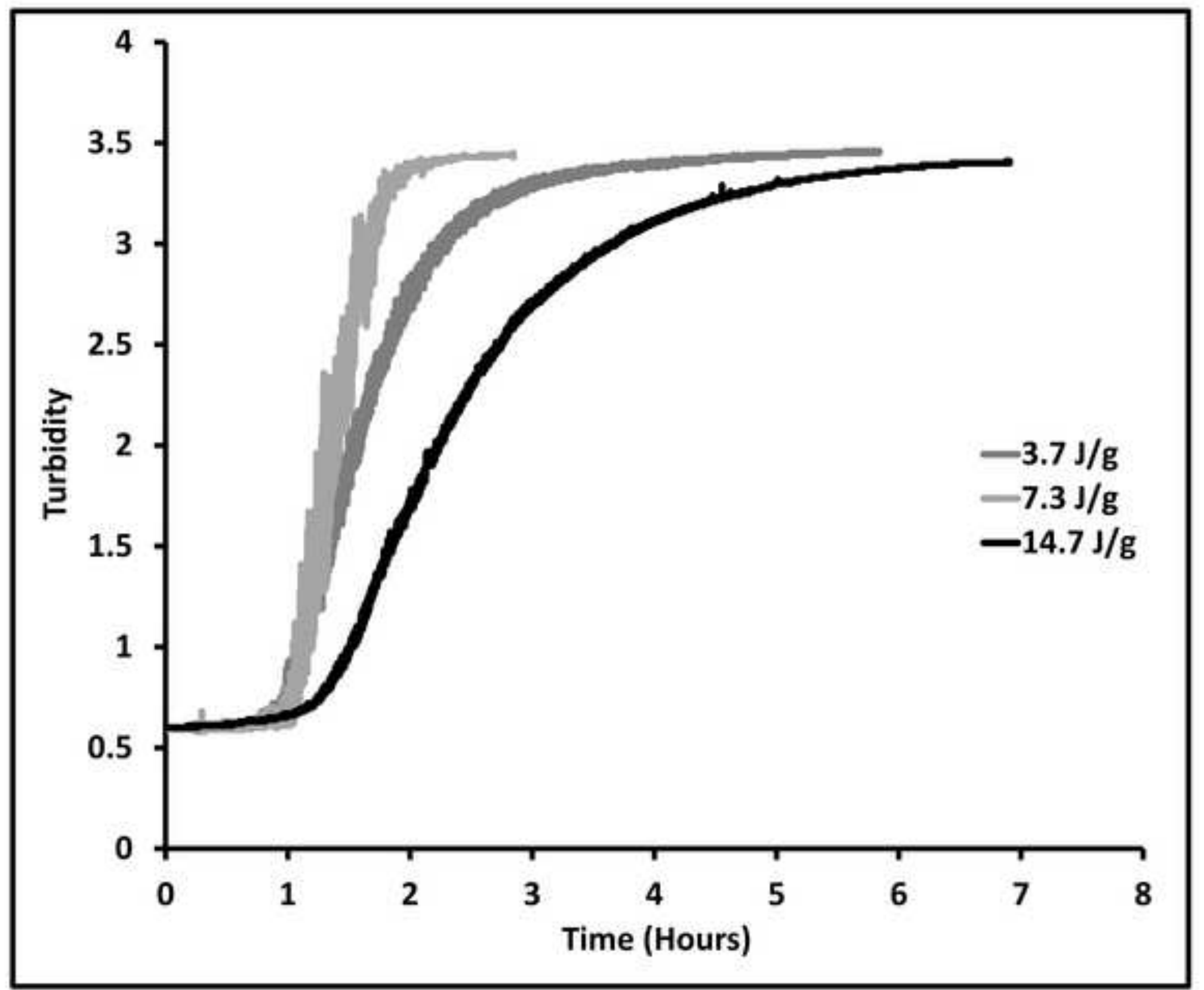




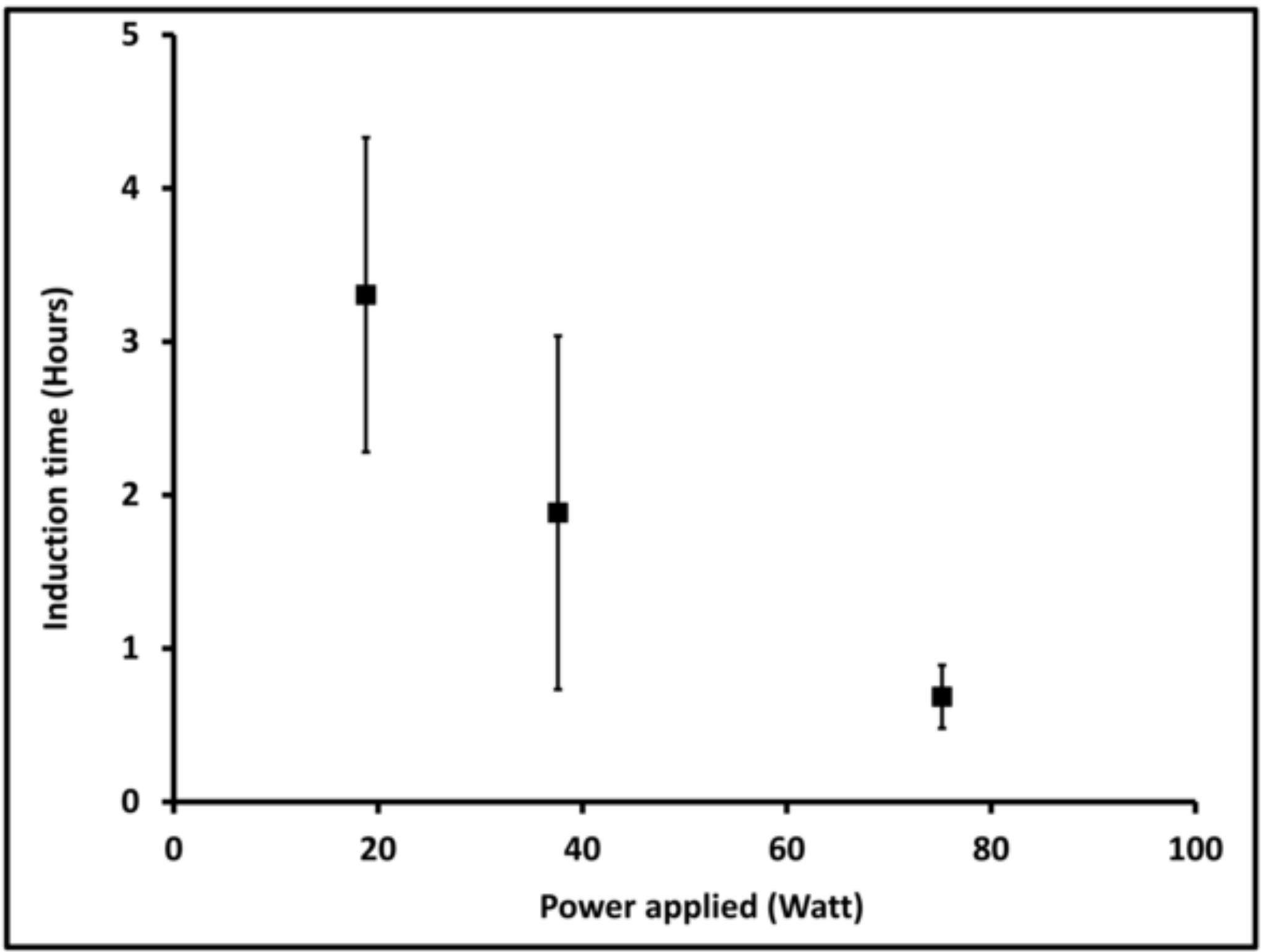




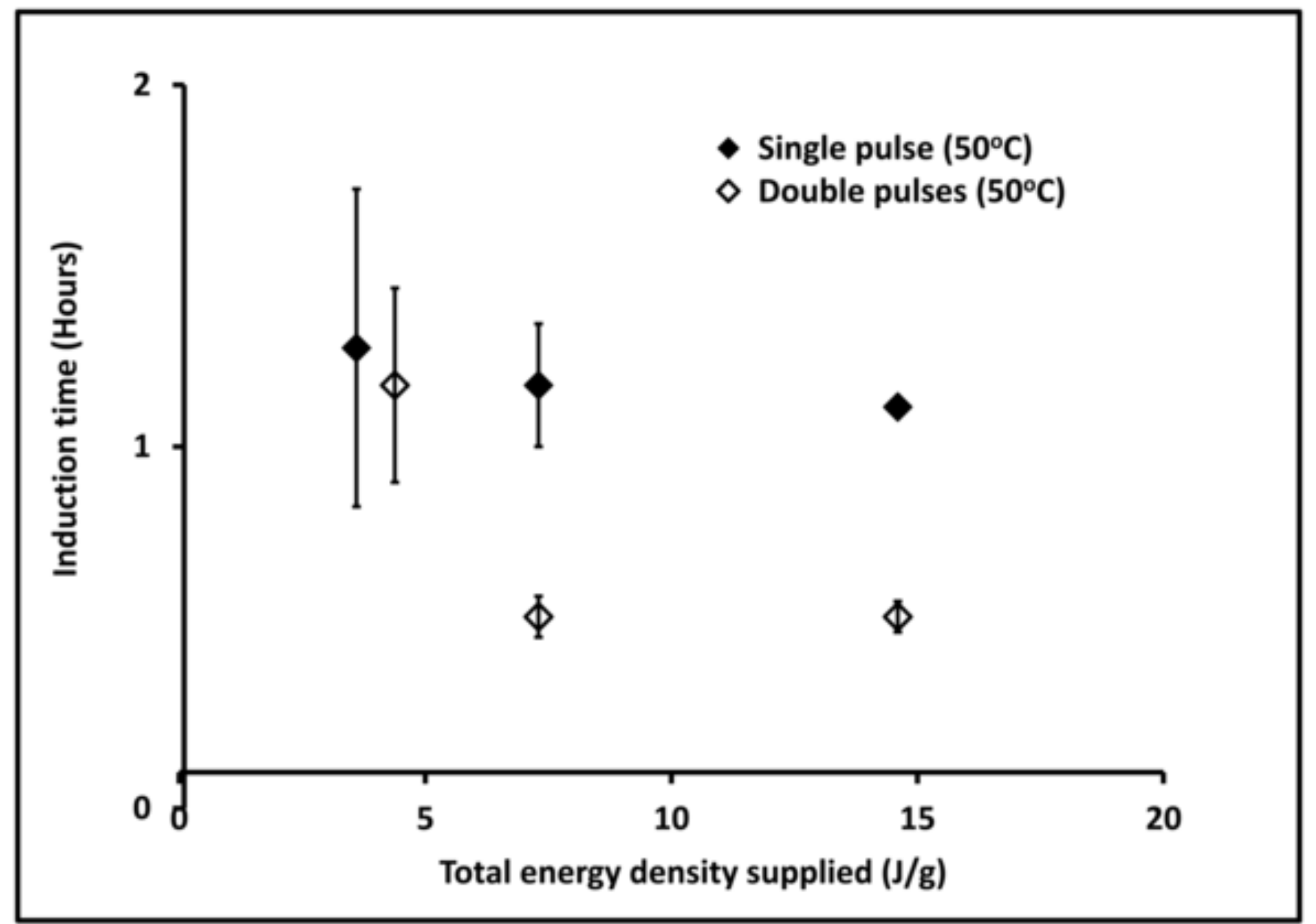


Figure 9a

Click here to download high resolution image

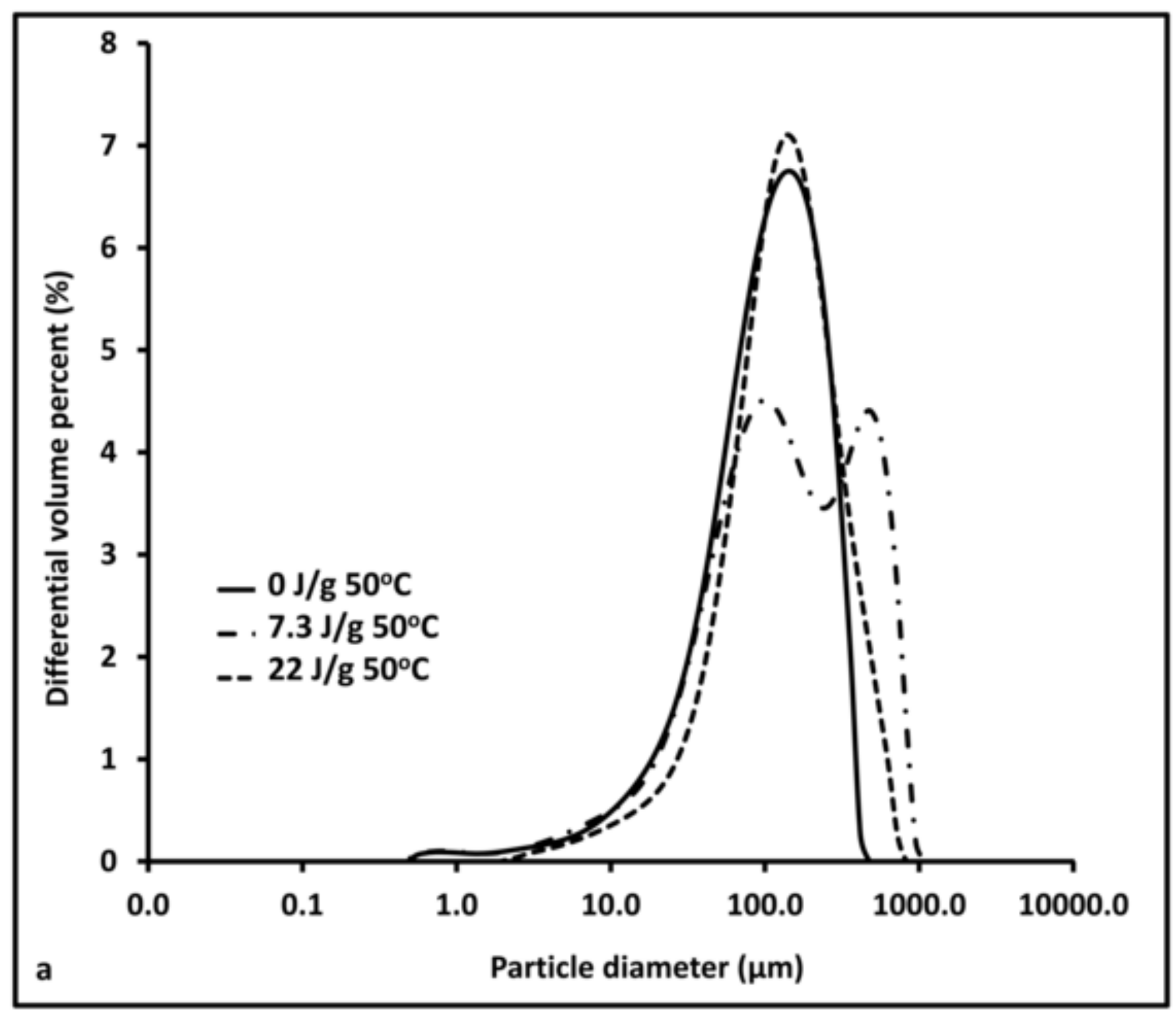




$$
\| \mathbb{N}
$$


Click here to download high resolution image

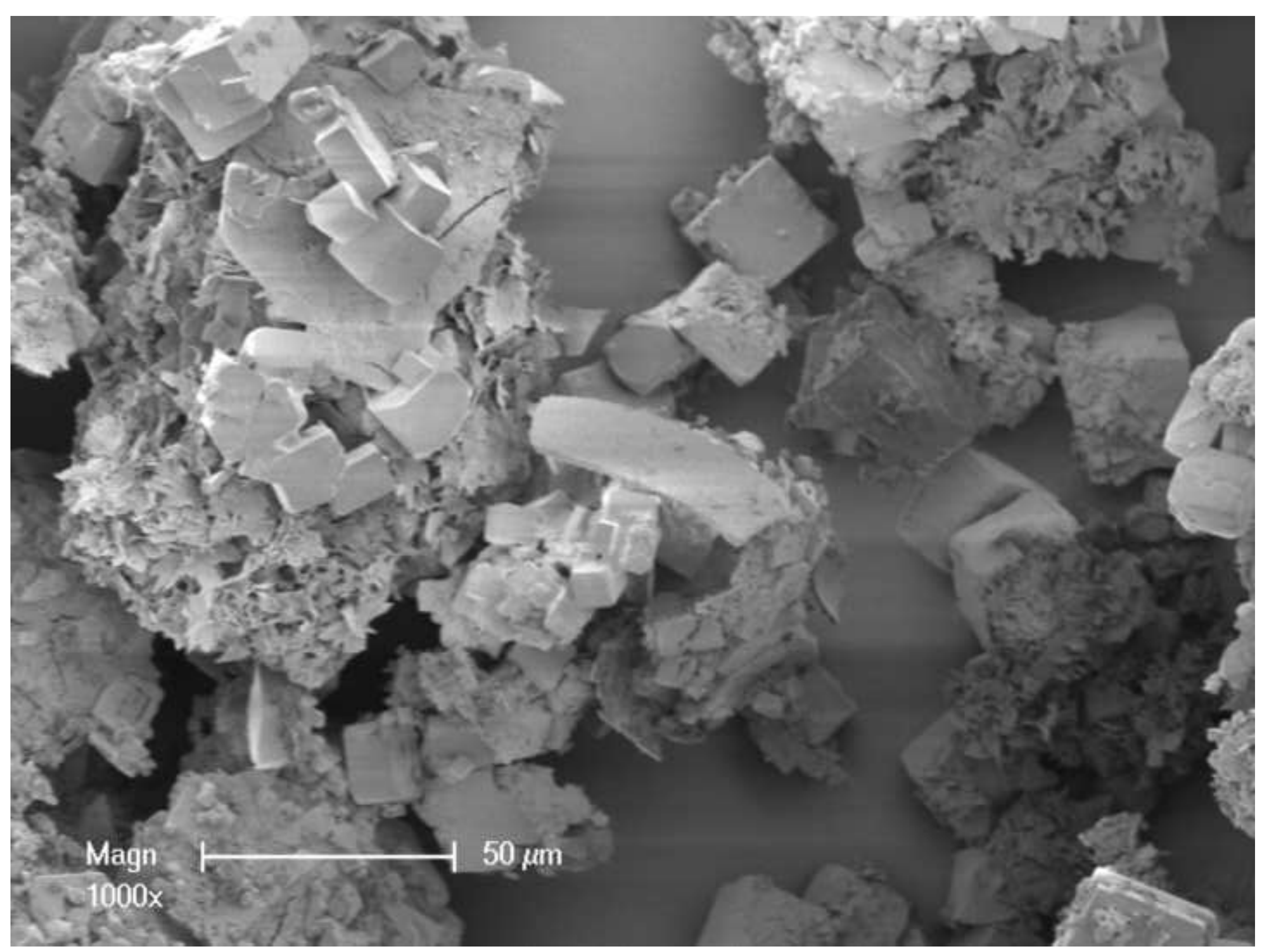


Click here to download high resolution image

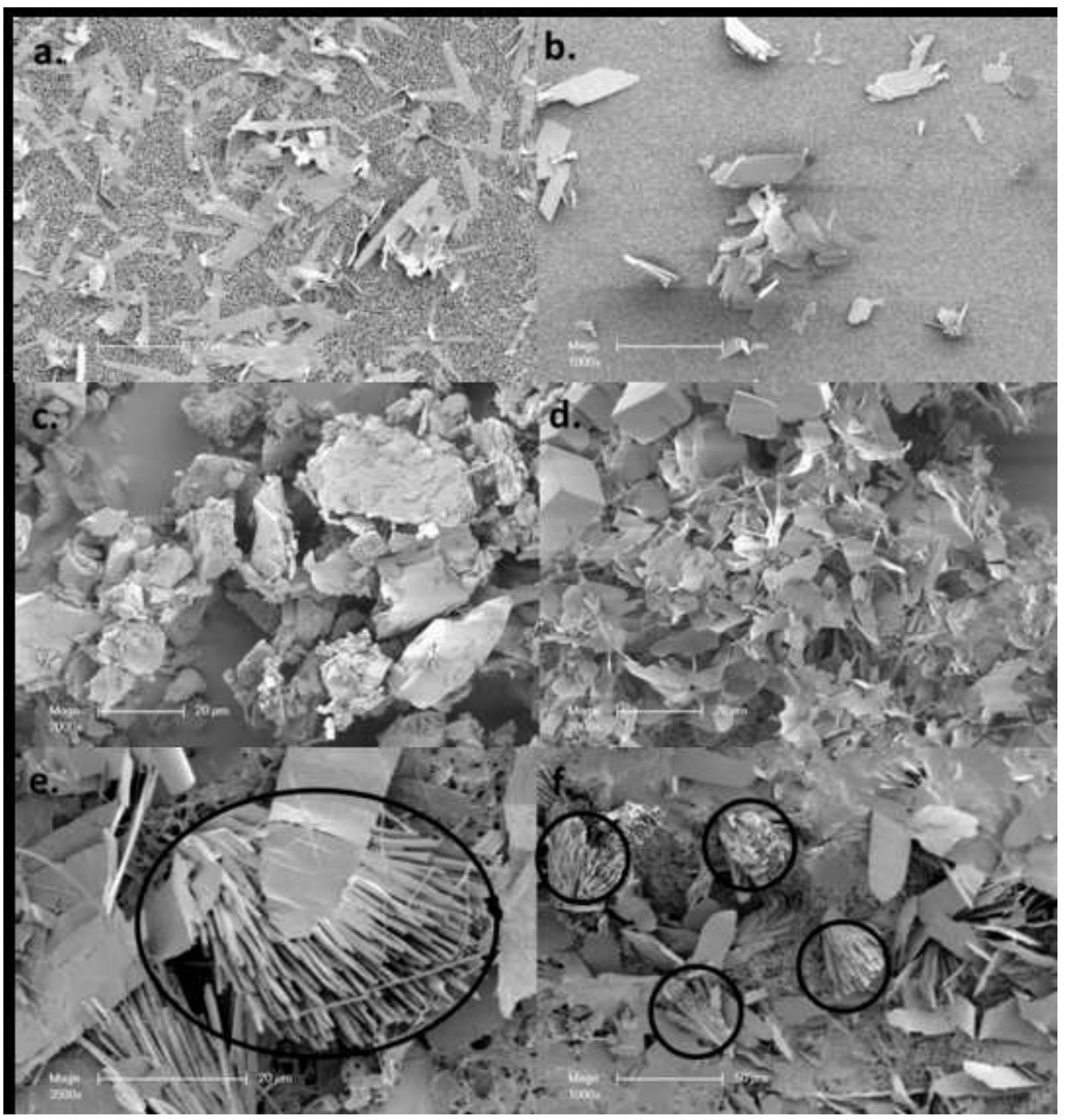




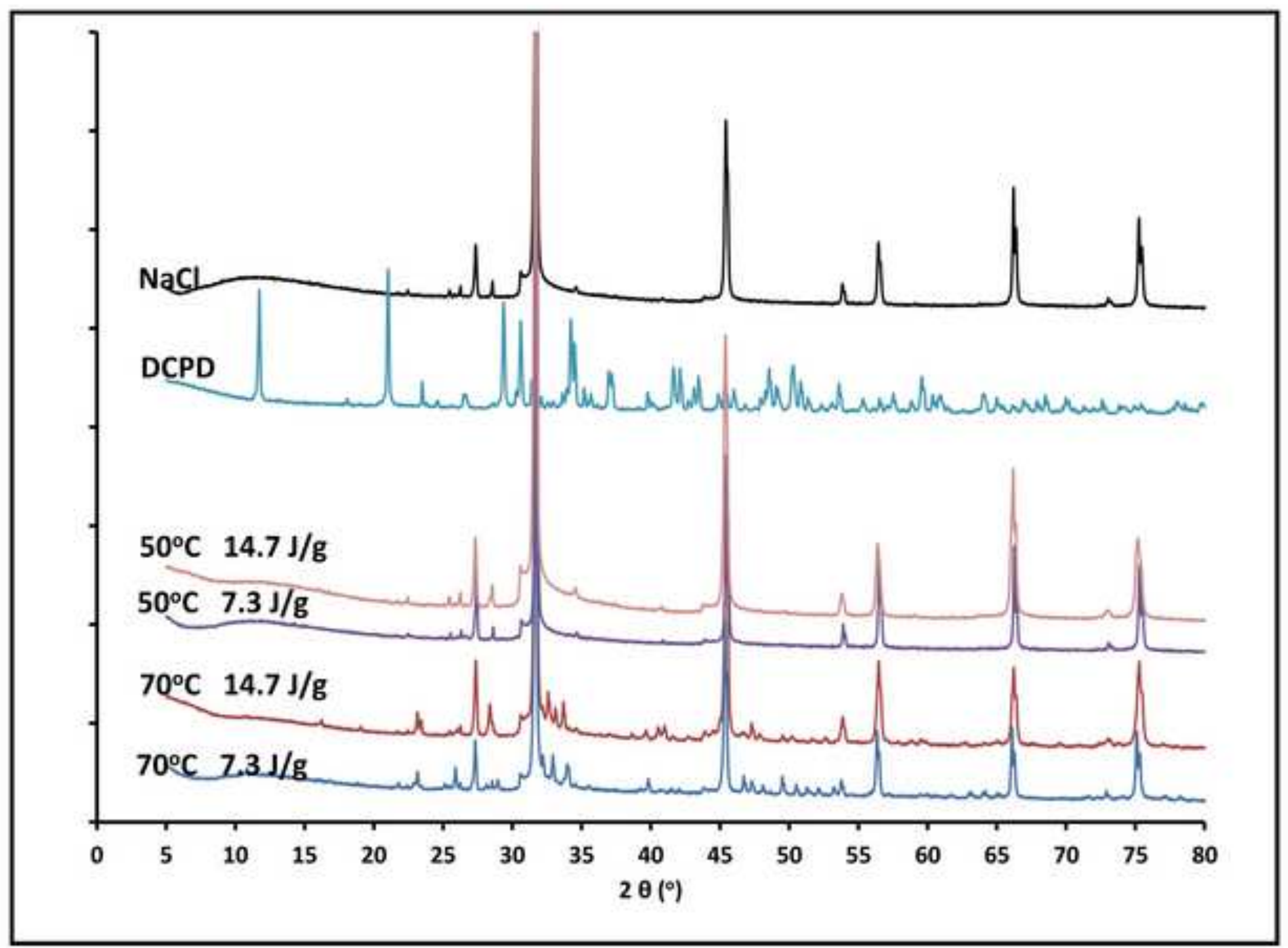




\section{University Library}

\section{- M M N E R VA A gateway to Melbourne's research publications}

Minerva Access is the Institutional Repository of The University of Melbourne

Author/s:

Kezia, K;Lee, J;Zisu, B;Weeks, M;Chen, G;Gras, S;Kentish, S

Title:

Crystallisation of minerals from concentrated saline dairy effluent

Date:

2016-09-15

Citation:

Kezia, K., Lee, J., Zisu, B., Weeks, M., Chen, G., Gras, S. \& Kentish, S. (2016).

Crystallisation of minerals from concentrated saline dairy effluent. WATER RESEARCH, 101, pp.300-308. https://doi.org/10.1016/j.watres.2016.05.074.

Persistent Link:

http://hdl.handle.net/11343/123248 